\title{
MULTI-PHASE NANOSTRUCTURED 60Si2Mn DISC SPRING BY A NOVEL AUSTEMPERING PROCESS
}

\author{
JIACHENG LI ${ }^{1}$, YUN HANG ${ }^{1}$, SHUANG ZHOU ${ }^{1}$, XUAN WANG $^{1}$, ZHONGYANG LIANG $^{1}$, \\ WENTAO ZHOU ${ }^{1}$, DEREK O. NORTHWOOD ${ }^{2} \&$ CHENG LIU $^{1}$ \\ ${ }^{1}$ School of Mechanical Engineering, Yanghzhou University, People's Republic of China \\ ${ }^{2}$ Department of Mechanical, Automotive and Materials Engineering, University of Windsor, Canada
}

\begin{abstract}
A disc spring, also known as a Belleville spring, is a conical shell which can be loaded along its axis either statically or dynamically. It can generate a high force in a very short spring length with minimal movement when compressed. A novel multi-step austempering heat treatment process is developed to improve both the hardness and strength of a conventional 60Si2Mn disc spring. In this case, the disc spring is austenitized at $900^{\circ} \mathrm{C}$ for $0.5 \mathrm{~h}$, control-quenched to a temperature below Ms (the starting temperature of martensite transformation) for a very short time, subsequently heated to the Ms point and holding for a specific time, and finally air cooled to the room temperature. It is found that the resulting multiphase microstructure consists mainly of prior lenticular martensite formed during controlled quenching (PM), needle bainitic ferrite (BF), and high carbon enriched retained austenite (RA). Further observation shows that a nanostructured (BF+RA)nano phase including lath $\mathrm{BF}$ and film RA with a width of about $100 \mathrm{~nm}$ nucleates around the PM. Such a microstructure results in uniform compression behavior, and significantly higher strength and hardness than for a conventional 60Si2Mn disc spring. This controlled multi-step austempering process is a promising solution for enhancing the disc spring properties for those applications involving higher loading and fatigue conditions.
\end{abstract}

Keywords: disc spring, multi-step austempering process, nanostructure, multi-phase, compression behavior.

\section{INTRODUCTION}

A disc spring is essentially a flat metal conical shaped spring that can be loaded along its axis at either the upper inner edge or the lower outer edge. Compared with other types of springs, it has a number of advantageous properties such as a wide range of load and deflection, high energy storage capacity with small deflection, long service life under dynamic load and is adaptable to stacking in numerous configurations [1]-[4]. On the basis of these excellent properties, the disc spring has been adopted in nearly all areas of technology during the last several decades [5]. However, with the rapid developments in the automotive, energy (wind turbines, power plants, energy storage), oil gas, machine tool, railway industries, the requirements for disc springs have become stricter and require this simple spring product to have a high fatigue strength with low stress relaxation [6], [7]. Two major approaches have been pursued to improve the fatigue strength of the disc spring. One is to control the metallurgical quality such as lowering the impurities or adding vanadium and/or chromium to the spring steel [6], [8]. However, not all disc spring manufacturers quality controls for the steels they use, or cover the product cost of alloying. The other approach of great interest is to produce residual compressive stress in the surface by shot peening [9]-[11]. However, there are some adverse effects on the fatigue strength caused by excessive shot peening, such as an increase in surface roughness and an uncontrollable stress distribution in disc spring surface [12], [13].

It is well known that the most effective way for improving the fatigue resistance is to increase the strength of disc spring itself [14], [15]. Varshney et al. [16], [17] and our previous work [18], [19] have shown that, a complex multiphase nano-structure produced by a multi- 
step austempering process can offer an exceptional tensile strength as well as an acceptable ductility in carbon steels. Therefore, such a multiphase nano-structure may also be useful in disc springs. However, most studies have been conducted on an austempering heat treatment above the starting temperature of the martensite transformation (Ms), and only a limited number of publications deal with the microstructural change and mechanical performance at the austempering temperature equal to Ms. No studies have been directed at a commercial product. Thus, the primary objective of this study is to examine whether this austempering is a viable heat treatment process for a conventional disc spring. Special attention is given to the influence of austempering time on microstructure and mechanical properties of the disc spring.

\section{EXPERIMENTAL PROCEDURES}

The chemical composition of the conventional spring steel (60Si2Mn) used for this study was Fe-0.64C-1.73Si-0.77Mn-0.19Cr-0.05Mo-0.03Ni-0.01P (wt.\%). Fig. 1(a) is a photograph of a commercial disc spring made from 60Si2Mn steel and Fig. 1(c) details the dimensions of the disc spring used for testing. Fig. 1(b) shows the microstructure of such a disc that has been subjected to the conventional heat treatment process. The microstructure consists of ferrite (F) and cementite (Cem).

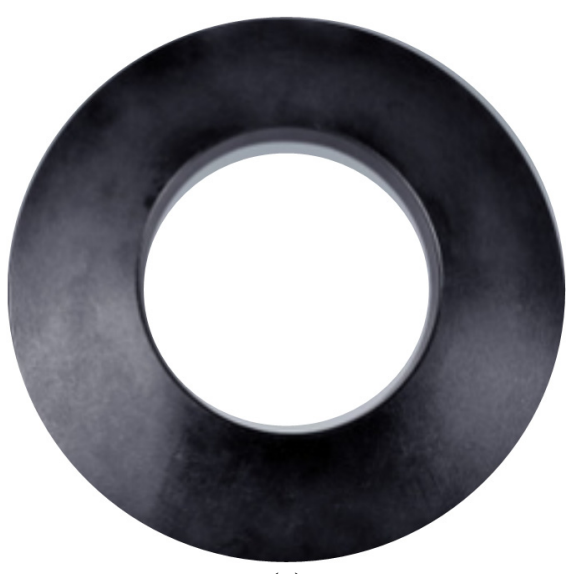

(a)

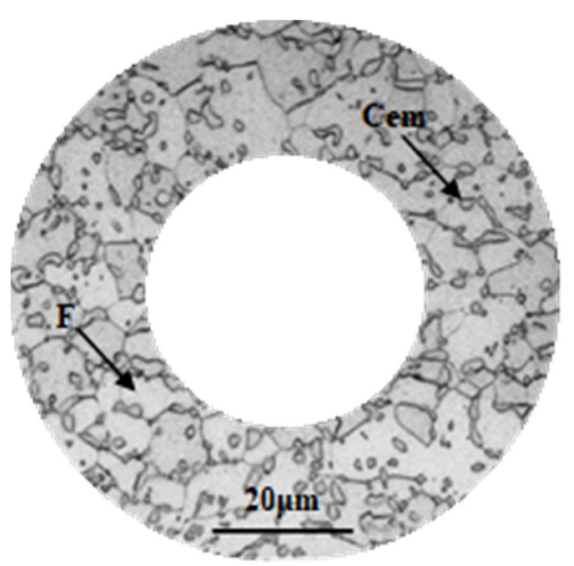

(b)

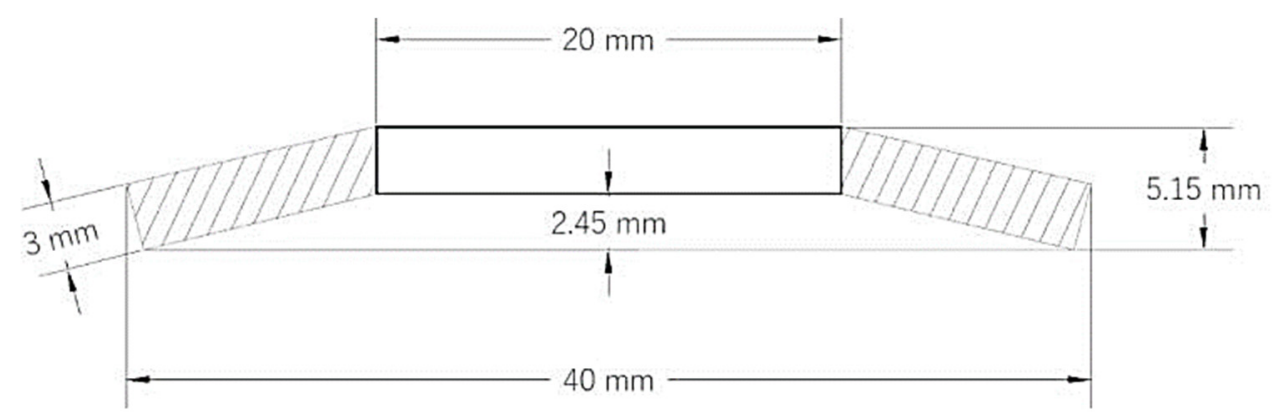

(c)

Figure 1: (a) Photograph; (b) $\mathrm{OM}$ micrograph of as-received disc spring; and (c) Schematic diagram showing disc spring size for the tests. 
Critical points of steel (Ac1, Ac3, and Ms) were selected at $763^{\circ} \mathrm{C}, 772^{\circ} \mathrm{C}$ or $227^{\circ} \mathrm{C}$ according to the equations in [20], and a multi-step austempering heat treatment (MAHT) process was applied. Fig. 2 schematically presents the heat treatment schedules for both the conventional and the designed MAHT processes. In the conventional method, the spring disc is heated to $860^{\circ} \mathrm{C}$ for 5 to 10 min for austenitization, followed by oil quenching, and was finally tempered at $460^{\circ} \mathrm{C}$ for $2 \mathrm{~h}$ to achieve the desired tempered troostite microstructure [21]. During the MAHT process, a disc spring is heated to $900^{\circ} \mathrm{C}$ for $30 \mathrm{~min}$, then quenched to $210^{\circ} \mathrm{C}$ (slightly lower than the $\mathrm{Ms}$ ) by controlled cooling in a patented water-based quenching liquid to prevent the formation of pearlite, ferrite or bainite. It is then austempered at $230^{\circ} \mathrm{C}$ (around $\mathrm{Ms}$ ) for varying times, and finally air cooled to the room temperature.

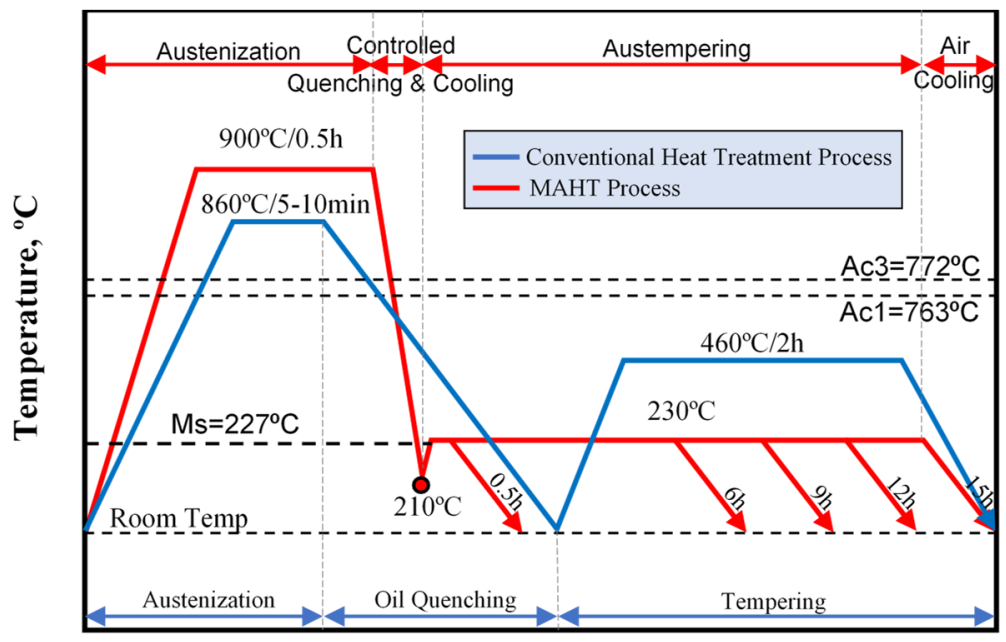

Time, h

Figure 2: Schematic of conventional heat treatment and MAHT processes of disc springs.

The load-deflection performance of the disc springs was determined using a DNS100 universal testing machine with a maximum load of $80 \mathrm{KN}$ for $30 \mathrm{~s}$, and a loading speed of $0.5 \mathrm{~mm} / \mathrm{min}$. Rockwell hardness measurements were made with a HR-150A Rockwell hardness tester. The mechanical properties were determined for both conventionally formed disc springs and the MAHT disc springs. The microstructures were examined using both optical microscopy (OM) and scanning electron microscopy (SEM). Image-Pro Plus 6.0 software was used to quantitatively evaluate the microstructure.

\section{RESULTS AND DISCUSSION}

The microstructures of the disc springs austempered at $230^{\circ} \mathrm{C}$ for 9 and $15 \mathrm{~h}$ are shown in Fig. 3. The optical micrographs (OM) in Fig. 3(a) and 3(c) show that a multiphase microstructure is obtained consisting of prior martensite (PM, dark black), bainitic ferrite (BF, grey) and retained austenite (RA, white) either in a film, or blocky, shape. The detailed SEM observations demonstrate that PM is lenticular with either carbides (Fig. 3(b)) or carbon clusters (Fig. 3(d)) inside the martensitic laths. A structure of fine lath BF and fine film RA with dimensions smaller lower than $100 \mathrm{~nm}((\mathrm{BF}+\mathrm{RA})$ nano) was found locally around the PM. This is shown in the white dashed circle areas in both Fig. 3(b) and 3(d). 


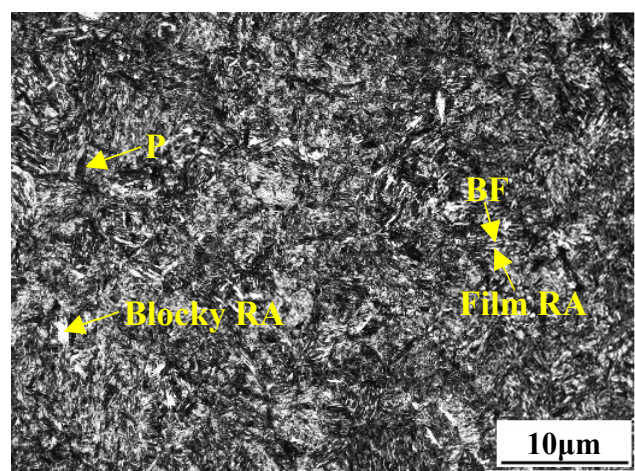

(a)

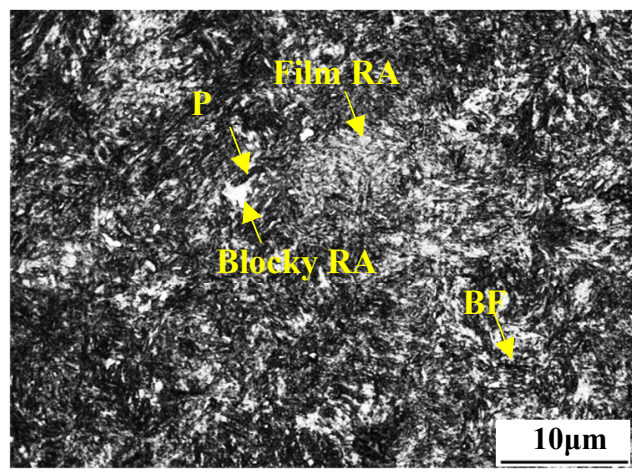

(c)

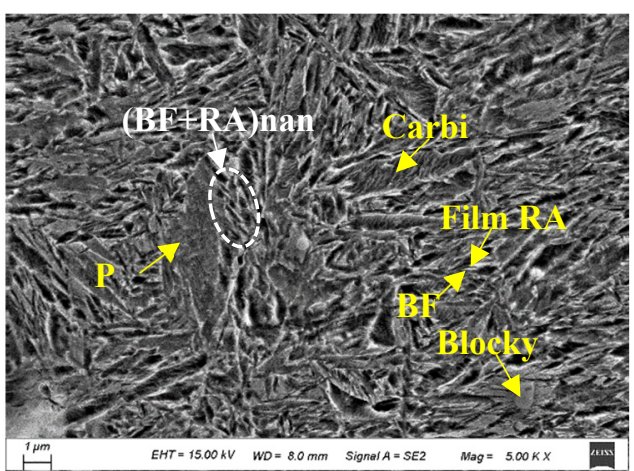

(b)

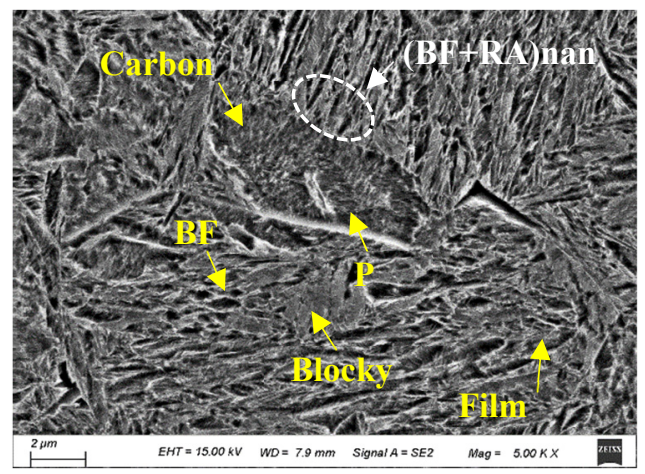

(d)

Figure 3: (a) $\mathrm{OM}$; (b) SEM micrographs of samples austempered at $230^{\circ} \mathrm{C}$ for $9 \mathrm{~h}$; (c) $\mathrm{OM}$; and (d) SEM micrographs of samples austempered at $230^{\circ} \mathrm{C}$ for $15 \mathrm{~h}$.

The disc compression test results performed for both disc springs heat treated using the MAHT process and for a conventionally heat treated disc spring are presented in Fig. 4. No cracks or damage was observed for all disc springs. Hence, the compressive behavior of the conventional and the MAHT process formed disc springs is comparable. Furthermore, Fig. 4 shows a much higher spring force for the disc springs which were austempered for times longer than $9 \mathrm{~h}$, compared to a conventional heat treated disc. The maximum spring force at a deflection of $1.3 \mathrm{~mm}$ was increased by $20 \%$ compared to the conventional disc spring.

The mechanical properties of MAHT processed disc springs compared with those subjected to a conventional heat treatment are shown in Fig. 5. It is clear that, the tensile strength which is obtained from the hardness-tensile conversion table according to the commercial specification [5], and the hardness increase slightly, when the austempering time is increased from 6 to $15 \mathrm{~h}$. Comparing the disc springs austempered for $15 \mathrm{~h}$ at $230^{\circ} \mathrm{C}$ with a conventionally processed disc spring, there is a $47 \%$ increase in tensile strength and a $20 \%$ increase in hardness.

It is important to note that the disc springs heat treated by the MATH process show better, or at least comparable, compressive performance to the conventional disc spring. Moreover, 


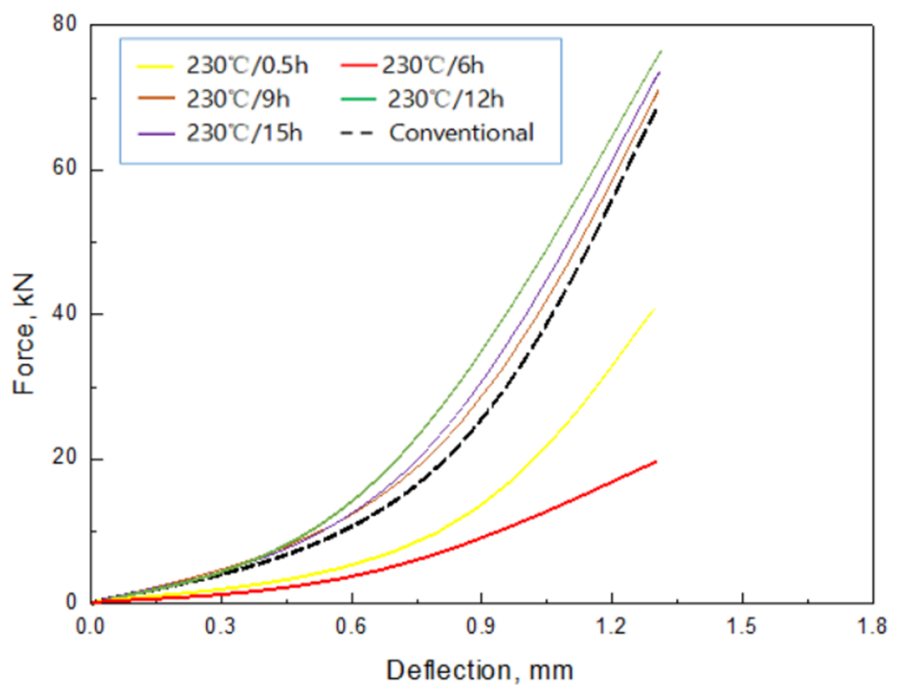

Figure 4: Experimental characteristic force-deflection curves of conventional and MAHT processes formed disc springs.

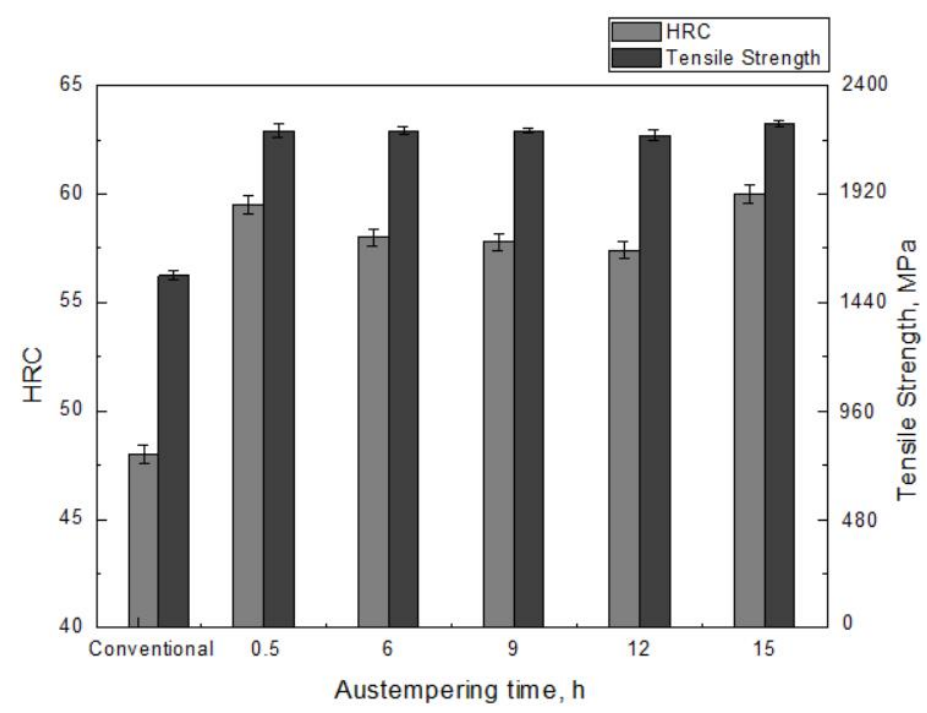

Figure 5: Relationship between tensile strength, hardness and austempering time.

they have a higher hardness, and a higher tensile strength, than the conventional one. It is well known that the microstructure of $60 \mathrm{Si} 2 \mathrm{Mn}$ disc spring is tempered troostite obtained by quenching and tempering at high temperature as the conventional heat treatment process, which provides appropriate strength and ductility [22]. Fig. 6 shows that, some microcracks (conventional heat treatment process) easily form at the confluences of martensitic laths, 


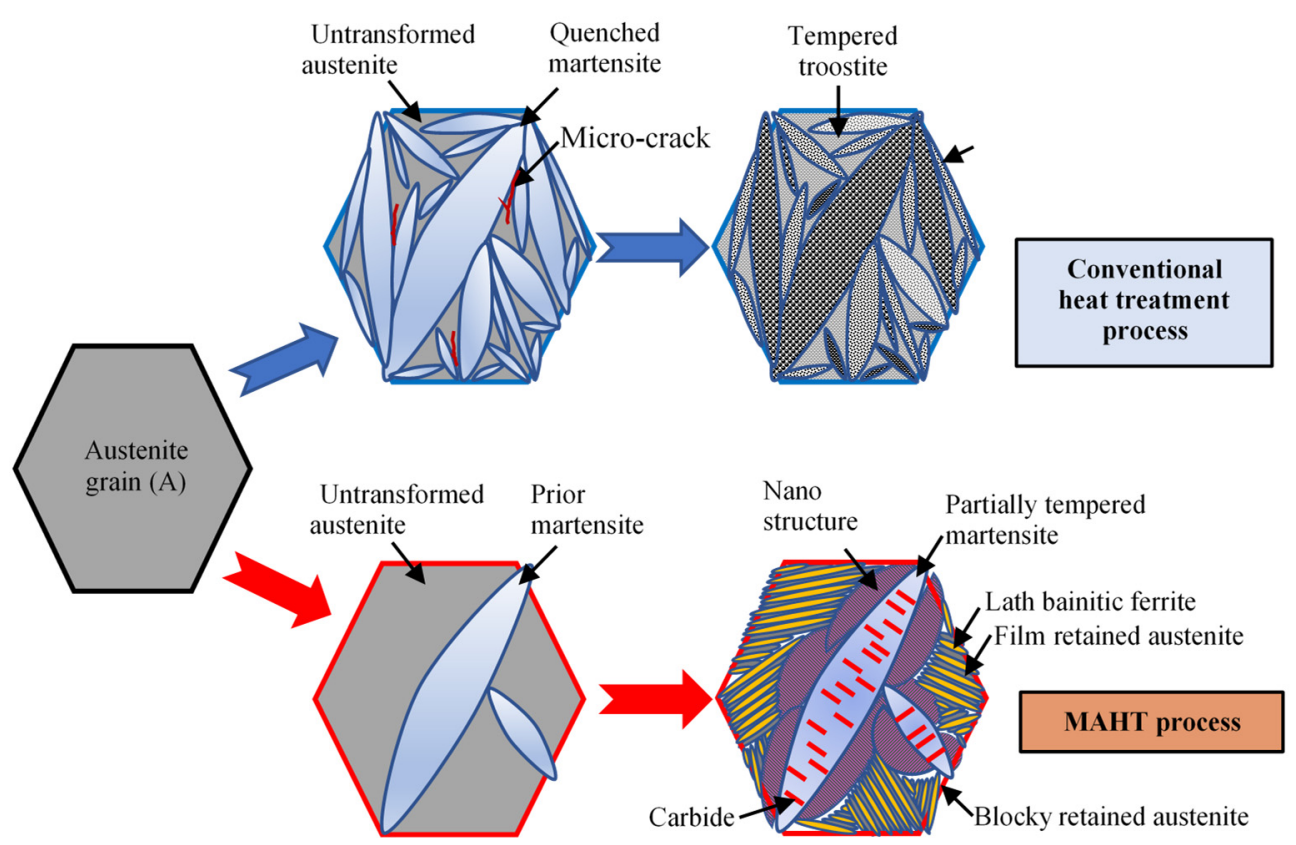

Figure 6: Schematic of microstructural evolution for conventional heat treatment and MAHT processes.

particularly as a large amount of martensite is obtained during quenching. Furthermore, the hard and brittle carbides will finally precipitate in the subsequent process of tempering at high temperature, although the Si content in the spring steel is fairly high to suppress precipitation of carbides during tempering. Thus, if formed, the carbides will be detrimental to the mechanical properties of disc spring [21], [23].

The microstructure in Fig. 6 schematically indicates that a MAHT process with low temperature tempering around $\mathrm{Ms}$ for longer duration, can potentially favor the formation of a unique multiphase microstructure. Compared to the conventional heat treatment process, a smaller amount of prior martensite (PM) is produced by the controlled quenching step in the MAHT process, which minimizes the possibility of microcrack formation. With respect to $\mathrm{PM}$, it has been reported [24]-[26] that a nanostructure consisting of bainitic ferrite (BF) laths and carbon-rich austenite $\left(\mathrm{A}_{+\mathrm{C}}\right)$ films with a size less than $100 \mathrm{~nm}$, prefers to nucleate around the PM. This is consistent with the microstructural observations in Fig. 3(b) and 3(d) (white circles). Moreover, at lower austempering temperature around the Ms, the ferrite laths are much narrower, as well as the austenite films (Fig. 3(b) and 3(d)). Based on these results, both the nano structure $\left(\mathrm{BF}+\left(\mathrm{A}_{+\mathrm{C}}\right)\right)$ and fine $\mathrm{BF}$ separated by film austenite produce a higher tensile strength, and higher hardness than the tempered troostite that is produced by the conventional heat treatment process. The high tensile strength and hardness of a high performance steel is significant. This is particularly true for medium-carbon alloyed steel, which is used for disc springs that are exposed to heavy loads [23].

Fig. 5 shows that both hardness and tensile strength increase with increasing austempering time at $230^{\circ} \mathrm{C}$. This can be explained by an increase on both lath BF and film RA with time. It has been found that the film austenite has a higher carbon concertation, higher dislocation 
density, and higher stability compared with block austenite [27]. Therefore, a disc spring with various microstructural constituents exhibits superior comprehensive properties due to synergistic strengthening and toughening effects. When the austempering time is short, such as $0.5 \mathrm{~h}$, austenite is less supersaturated with carbon and less stable, and thus transforms into quenched martensite during the final cooling step of the MATH process. This results in a higher hardness, but degrades the performance under compressive loads.

\section{CONCLUSIONS}

A novel multi-step austempering heat treatment process for producing disc springs from 60Si2Mn steel is proposed. A disc spring is successfully formed using the proposed process with comparable or better compression behavior, and a higher calculated tensile strength and a higher hardness, compared to the conventional heat treatment process. This trend is attributed to synergistic strengthening and toughening effects from the formation of a nano multi-phase microstructure.

\section{REFERENCES}

[1] Hajavifard, R., Maqbool, F., Schmie-Kalenborn, A., Buhl, J., Bambach, M. \& Walther, F., Integrated forming and surface engineering of disc spring by inducing residual stresses by incremental sheet forming. Materials, 1646, pp. 1-19, 2019.

[2] Yi, X.Z., The mechanics properties research of the disc spring. Proceedings of 2015 International Conference on Computer Science and Environmental Engineering (CSEE 2015), pp. 230-236, 2015.

[3] Dharan, C.K.H. \& Bauman, J.A., Composite disc springs. Composites Part A, 38(12), pp. 11-16, 2007.

[4] Kobelev, V., Durability of Springs, Springer: London, 270 pp., 2018.

[5] Fromm, E. \& Kleiner, W., Handbook for Disc Springs, Schnorr Corporation: Ann Arbor, MI, pp. 55-64, 2018.

[6] Niu, G., Chen, Y.L., Wu, H.B., Wang, X., Zuo, M.F. \& Xu, Z.J., Effects of chromium, vanadium and austenite deformation on transformation behaviors of high-strength spring steels. Journal of Iron and Steel Research International, 23, pp. 23-32, 2016.

[7] Maqbool, F., Hajavifard, R., Walther, F. \& Bambach, M., Engineering the residual stress state of the metastable austenitic stainless steel (MASS) disc springs by incremental sheet forming (ISF). Production Engineering, 13, pp. 139-148, 2019.

[8] Zhang, C.L., Liu, Y.Z., Jiang, C. \& Xiao, J.F., Effects of niobium and vanadium on hydrogen-induced delayed fracture in high strength spring steel. Journal of Iron and Steel Research International, 18(6), pp. 49-53, 2011.

[9] Ongtrakulkij, G., Khantachawana, A. \& Kondoh, K., Effects of media parameters on enhance ability of hardness and residual stress of Ti6Al4V by fine shot peening. Surfaces and Interfaces, 18, pp. 100-424, 2020.

[10] Wu, J.Z., Liu, H.J., Wei, P.T., Zhu, C.C. \& Lin, Q.J., Effect of shot peening coverage on hardness, residual stress and surface morphology of carburized rollers. Surface and Coatings Technology, 384, pp. 125-173, 2020.

[11] Zhou, F., Jiang, W.C., Yang, B. \& Xiao, C.R., A comprehensive numerical approach for analysing the residual stresses in AlSl 301LN stainless steel induced by shot peening. Materials (Basel, Switzerland), 12(20), pp. 12-14, 2019.

[12] Martín, V., Vázquez, J., Navarro, C. \& Domínguez, J., Effect of shot peening residual stresses and surface roughness on fretting fatigue strength of Al 7075-T651. Tribology International, 142, pp. 141-152, 2020. 
[13] Zhang, J.W., Li, H., Bing, W., Wu, B. \& Zhu, S.D., Fatigue properties and fatigue strength evaluation of railway axle steel: Effect of mico-shot peening and artificial defect. International Journal of Fatigue, 132, pp. 141-152, 2020.

[14] Komec, A., Dikci, K., Atapek, S.H., Polat, S. \& Celik, G.A., Microstructure and mechanical characterization of the parabolic spring steel 51CrV4. Materials Testing, 2, pp. 11-12, 2017.

[15] Liu, S.Y., Liu D.Y. \& Liu, S.C., Effect of heat treatment on fatigue resistance of spring steel 60Si2CrVAT. Metal Science and Heat Treatment, 52(1-2), pp. 57-60, 2010.

[16] Varshney, A., Sangal, S., Kundu, S. \& Mondal, K., Super strong and highly ductile low alloy multiphase steels consisting of bainite, ferrite and retained austenite. Materials and Design, 95, pp. 75-88, 2016.

[17] Varshney, A., Sangal S., Kundu, S. \& Mondal, K., Microstructural evidence of nanocarbides in medium carbon high silicon multiphase steels. Material Science and Engineer A, 708, pp. 37-47, 2017.

[18] Cui, X.X., Northwood, D.O. \& Liu, C., Role of prior martensite in a 2.0 GPa multiple phase steel. Steel Res. Int., 89, 1800207, pp. 1-8, 2018.

[19] Liu, C., Cui, X.X. \& Yang, C., Multiphase microstructure in a metastability-assisted medium carbon alloy steel. J. Mater. Eng. and Performance, 27(32), pp. 39-47, 2018.

[20] Leslie, W.C., The Physical Metallurgy of Steels, Hemisphere Publishing: Washington, 1981.

[21] Kim, S.H., Kim, K.H., Bae, C.M., Lee, J.S. \& Suh, D.W., Microstructure and mechanical properties of austempered medium-carbon spring steel. Metals and Materials International, 24, pp. 693-701, 2018.

[22] Sun, Y.H., Wang, K.H., Politis, J.D., Cai, Z.H. \& Wang, L.L., A novel warm stamping process for manufacturing disc springs. Advanced High Strength Steel and Press Hardening, 275, pp. 295-300, 2019.

[23] Fragoudakis, R., Savaidis, G. \& Michailidis, N., Optimizing the development and manufacturing of 56SiCr7 leaf springs. International Journal of Fatigue, 103, pp. 168$175,2017$.

[24] Liang, Z.Y., Zhou, W.T., Wang, X., Northwood, D.O. \& Liu, C., A 2.1 GPa triplephase spring steel. WIT Transactions on The Built Environment, vol. 175, WIT Press: Southampton and Boston, pp. 1-7, 2019.

[25] Yang, C., Cui, X.X. \& Liu, C., Multiphase matrix structure of unalloyed austempered ductile iron. Material Science and Technology, 34, pp. 261-267, 2018.

[26] Toji, Y., Matsuda, H. \& Raabe, D., Effect of Si on the acceleration of bainite transformation by pre-existing martensite. Acta Materialia, 116, pp. 250-262, 2016.

[27] Królicka, A., Radwański, K., Ambroziak, A. \& Żak, A., Analysis of grain growth and morphology of bainite in medium-carbon spring steel. Materials Science and Engineer A, 768, pp. 12-14, 2019. 